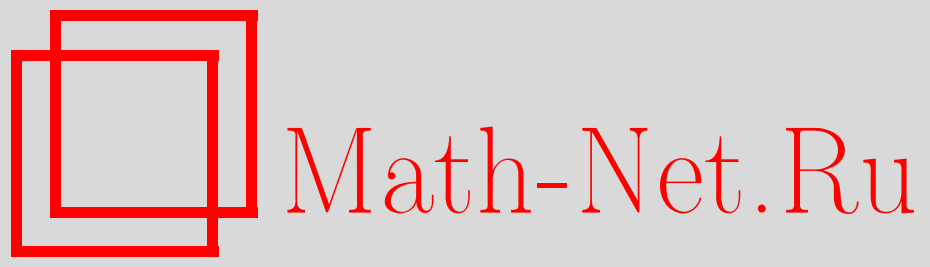

Н. Долбилин, Георгий Феодосьевич Вороной, Квант, 2018, номер 12, 2-7

DOI: https://doi.org/10.4213/kvant20181201

Использование Общероссийского математического портала Math-Net.Ru подразумевает, что вы прочитали и согласны с пользовательским соглашением http://www . mathnet.ru/rus/agreement

Параметры загрузки:

IP : 34.229 .45 .116

26 апреля 2023 г., 13:14:26

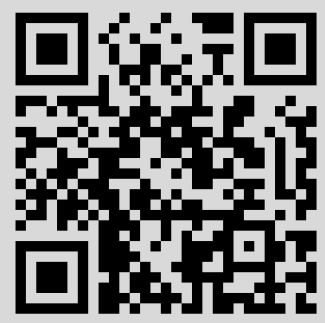




\section{Георгий Феодосьевич Вороной}

Н.ДОлБИлин

ЕОРГИЮ ФЕОДОСЬЕВИЧУ ВОРОНОМУ
судЬбой бЫЛО отмерено всего сорок лет. За свою короткую жизнь Вороной опубликовал не так много: 6 больших мемуаров и 6 относительно небольших заметок, всего 12 работ.

Однако имя Г.Ф.Вороного навсегда вписано золотыми буквами в историю науки как одного из крупнейших математиков, когда-либо работавших в теории чисел. Наряду с Г.Минковским Вороной является создателем новой области математики геометрии чисел, а знаменитые «диаграммы Вороного» не только стали геометрическим инструментом исследований в математике, в физике, в кристаллографии, в химии, в геологии, но и нашли применение даже в кинематографе.

\section{Детство}

Георгий Феодосьевич Вороной родился 16(28) апреля 1868 года в украинской семье в имении своего отца - в селе Журавка, расположенном в очень живописном уголке Полтавской губернии Российской империи (ныне Черниговской области Украины). Отец Вороного получил филологическое образование в Киевском университете и преподавал русскую литературу в гимназии, работал директором гимназий в Бердянске, Кишиневе, Прилуках.

Георгий Вороной начал свое школьное образование в Бердянске, а закончил в Прилукской гимназии в 1885 году. Вороной вел дневник, из которого мы знаем многое о его жизни. В частности, детство его протекало в очень теплой семейной атмосфере. У мальчика было несколько серьезных увлечений: музыка (Георгий играл на двух инструментах: на фортепьяно и флейте), шахматы, литература, са-

DOI: https://doi.org/10.4213/kvant20181201

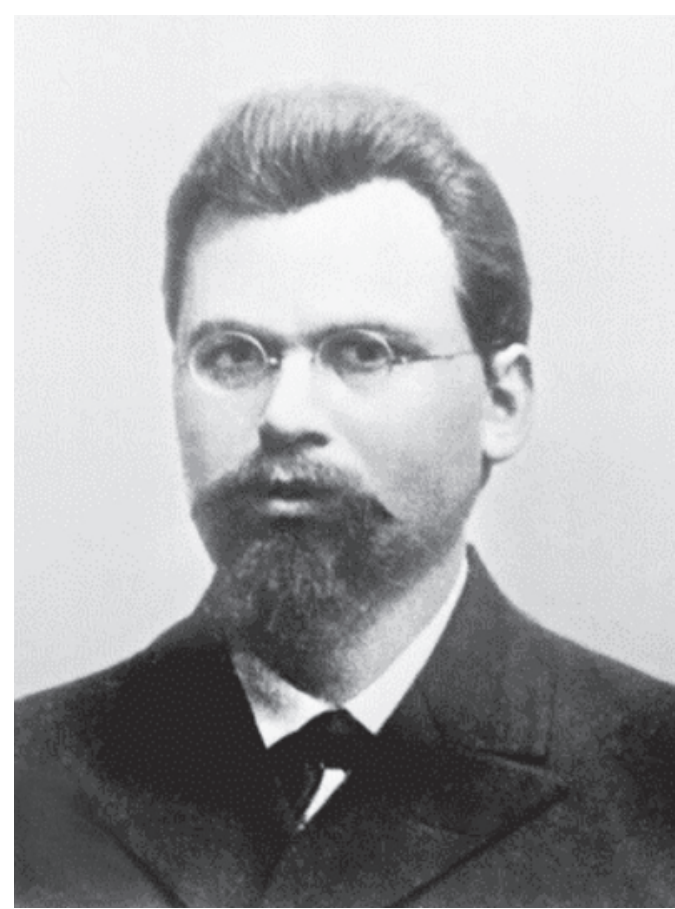

Георгий Феодосьевич Вороной (1868-1908)

модеятельный театр, в котором он исполнял роли и ставил спектакли.

В гимназические годы у Георгия проявились незаурядные математические способности. Развитию его математического дарования содействовал учитель математики Иван Владимирович Богословский. Этот замечательный педагог оказал огромное влияние также на общее развитие Вороного, в том числе и на его литературные интересы. В университете Вороной, как и все студенты того времени, был увлечен идеями и творчеством Л.Н.Толстого. Ему также нравились реалистичные описания русской жизни, которые он находил в произведениях П.И.Мельникова-Печерского «В лесах» и «На горах». В то же время Вороной оставался равнодушным к 


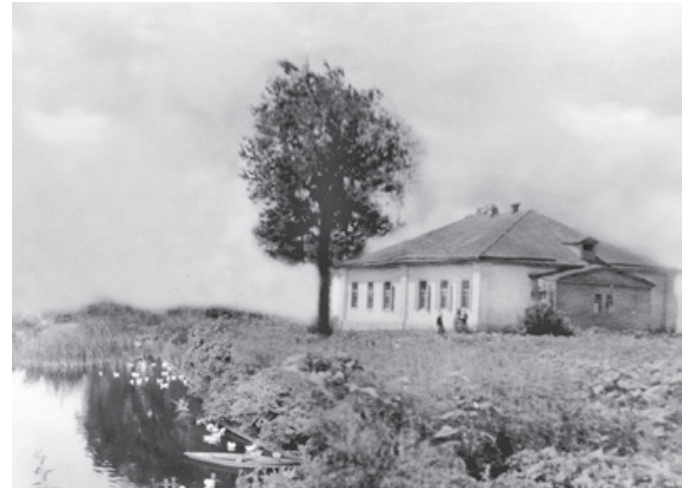

Дом Вороного в Журавке

творчеству М.Е.Салтыкова-Щедрина. Однако его гимназический учитель математики, который сам был страстным почитателем творчества Щедрина, сумел передать это отношение и студенту Вороному, своему бывшему ученику.

В 1884 году профессор Киевского университета, известный математик В.П.Ермаков начал издавать «Журнал элементарной математики». В нем он предложил несколько тем для ученических работ по математике. На одну из них, а именно на тему «Разложение многочленов на множители, основанное на свойствах корней квадратных уравнений», была представлена единственная работа. Ее автором был Вороной. Работа понравилась Ермакову, и он опубликовал ее в своем журнале в 1885 году. В том же году Вороной закончил гимназию и поступил в Петербургский университет.

\section{Учеба в Петербургском университете}

Из дневника мы знаем, с каким огромным желанием и настойчивостью Георгий приступил к изучению математических курсов, которые «все более увлекали» его. Он приучился вставать около 5 утра и приступал к занятиям, которые продолжались до вечера. У Георгия была при себе иголка, которой он укалывал себя, чтобы острой болью сбить накатывавшуюся время от времени волну усталости.

В бытовом отношении жизнь студента Вороного складывалась непросто. Материальной помощи, которую мог оказать отец, явно не хватало. А после выхода отца в отставку в 1887 году и эта помощь сократилась. Так как университетскую стипендию Вороной начал получать лишь на последнем курсе, то он был вынужден давать за небольшие деньги уроки. Уроки его выматывали, а тяжелые условия в общежитии дополнительно осложняли и отдых и занятия математикой.

В этих условиях Вороной сконцентрировал все силы и волю на математике. «Главное, что меня занимает, есть ли у меня достаточно способностей», - пишет он в дневнике. К счастью, математических способностей у Вороного было в избытке, а «постоянно усиливающаяся страсть к математике» захватила его всецело. В «моменты, когда ум охватывает идею, которая раньше как мячик ускользала, я забываю, что я существую», - записывает в дневнике Вороной в 1887 году. Там же: «моими последними успехами я обязан привычке мыслить без пера и бумаги. Все предложения, доказанные мною, возникали совершенно независимо. ...Я надеюсь, что эта привычка мыслить таким образом сослужит мне службу».

Чтобы дополнительно развить математические способности, Вороной устраивал себе математический тренинг: последовательно решал трудные учебные задачи на вычисление сложных интегралов и симметрических функций, на интегрирование дифференциальных уравнений.

К счастью, в Петербургском университете в то время действовала блестящая математическая школа гениального математика Пафнутия Львовича Чебышёва (1821-1894), знаменитая Петербургская школа теории чисел. Чебышёв и его выдающиеся ученики А.А.Марков (старший), А.М.Ляпунов, А.Н.Коркин и др. поддерживали очень высокий уровень математического образования в Петербургском университете.

Научным руководителем Вороного стал академик Андрей Андреевич Марков. Под его руководством Вороной исследовал бернуллиевы числа, названные так еще в XVIII веке в честь представителя знаменитой математической династии Якова Бер- 
нулли. Бернуллиевы числа $B_{s}$ вводятся рекуррентно и интересны, например, тем, что через них выражается сумма первых $N$ натуральных чисел, возведенных в данную степень $k$ :

$$
\sum_{n=0}^{N-1} n^{k}=\frac{1}{k+1} \sum_{s=0}^{k} C_{k+1}^{s} B_{s} N^{k+1-s} .
$$

Важность чисел Бернулли проявляется в разных областях математики: от теории чисел, где, например, Эйлер установил связь бернуллиевых чисел со значениями знаменитой $\zeta$-функции Римана при четных значениях аргумента, до алгебраической топологии. Действительно, числа Бернулли вошли в топологию благодаря фундаментальным работам Ф.Хирцебруха, которые привели, в частности, к красивым результатам М.Кервера и Дж.Милнора о гомотопических группах сфер. Изучению свойств этих чисел посвящено много работ известных математиков.

Числа Бернулли $B_{s}$ суть рациональные числа. Вороной в очень остроумной работе доказал следующее свойство бернуллиевых чисел. Пусть номер $s$ бернуллиева числа $B_{s}$ делится на $m$, а знаменатель числа $B_{s}$ взаимно прост с $m$. Тогда числитель числа $B_{s}$ делится на $m$.

Работа о бернуллиевых числах очень понравилась Маркову, и он рекомендовал ее к опубликованию. Вороной, требовательный и к себе и к работе, продолжал еще некоторое время улучшать рукопись. Статья «О числах Бернулли» вышла в «Сообщениях Харьковского математического общества» в 1890 году, через год после окончания университета. По результатам этих исследований Вороной защитил кандидатскую диссертацию (аналог нынешней дипломной работы) и был оставлен при университете «для подготовки к профессорскому званию» ( соответствует нынешней аспирантуре).

К этому времени Вороной сложился в профессионального математика, сосредоточившего свои усилия на теории чисел. После окончания университета Вороной начинает исследования по теории алгебраических чисел.

Число называется алгебраическим, если оно является корнем некоторого многочлена с рациональными коэффициентами $a_{i}$ :

$$
f(x)=a_{0} x^{n}+a_{1} x^{n-1}+\ldots+a_{n} .
$$

Интерес к теории алгебраических чисел во многом был вызван ее связью с важным классом диофантовых уравнений ${ }^{1}$

$$
f(x, y)=m,
$$

где $f(x, y)$ - однородный многочлен $n$-й степени или, как иначе говорят, форма $n$-й степени от двух переменных с целыми коэффициентами. В случае $n=2$ такие уравнения были полностью исследованы в работах великих математиков Эйлера, Лагранжа и др. Однако случай $n=3$ в конце XIX века оставался почти неизученным.

Вороной начал исследование алгебраических чисел степени $n=3$. Число $\alpha$ является алгебраическим числом степени 3 , если минимальная степень среди степеней всех многочленов с рациональными коэффициентами, для которых $\alpha$ является корнем, равна 3. Очевидно, что многочлен минимальной степени для данного $\alpha$ не может разлагаться в произведение многочленов меньших степеней, коэффициенты которых также рациональны. Такой многочлен с рациональными коэффициентами, который не разлагается в произведение многочленов меньших степеней, называется неприводимым.

Магистерская диссертация Вороного (аналог нынешней кандидатской диссертации) «О целых алгебраических числах, зависящих от корня неприводимого уравнения 3-й степени» содержала первые результаты, полученные автором по данной теме, и была успешно защищена в Петербургском университете в 1894 году.

\section{Работа в Варшавском университете}

После защиты Вороной был назначен профессором математики Императорского Варшавского университета. В то время (после Венского конгресса 1815 года и

\footnotetext{
${ }^{1}$ Пусть $p\left(x_{1}, \ldots, x_{n}\right)-$ многочлен степени $n>$ $>0$ с рациональными коэффициентами, тогда уравнение вида $p\left(x_{1}, \ldots, x_{n}\right)=0$, для которого ищутся решения в целых или рациональных числах, называется диофантовым.
} 
вплоть до 1915 года) Польша входила как Царство Польское в состав Российской империи.

В университете Вороной читал курсы по основным математическим предметам. Одним из его учеников был выдающийся польский математик Вацлав Серпинский (1882-1969), которому принадлежит много достижений в разных областях математики. Серпинский выполнил под руководством Вороного работу по аналитической теории чисел.

Вороной продолжил исследования по теории алгебраических чисел 3-й степени. Он построил эффективный алгоритм для вычисления так называемых основных единиц кубического поля.

Это был очень сильный результат, поскольку знаменитая теорема Дирихле о единицах утверждала, что основные единицы в алгебраическом поле существуют. Однако она не давала никакого пути для их нахождения.

Алгоритм нахождения основных единиц для кубических полей, построенный Вороным, настолько поразил А.А.Маркова, что он послал Вороному телеграмму в Варшаву с просьбой срочно приехать в Петербург. Вороной так и поступил. Как только он появился в кабинете своего научного руководителя, ему тут же предложили найти основные единицы для одного частного случая, для которого Маркову самому удалось найти их при помощи весьма сложных вычислений. Поэтому Марков был восхищен, когда Вороному понадобилось всего три часа, чтобы посредством своего алгоритма решить задачу.

Замечательные результаты Вороного по этой теме были описаны в его последней, докторской, диссертации, блестяще защищенной в 1897 году. В этой диссертации, как писал Б.Н.Делоне, Вороной «мыслил геометрически, но вынужден был переводить ход своих рассуждений на арифметический язык». Парадоксально, но факт: руководители Петербургской школы теории чисел и особенно Марков, основной оппонент по диссертации, не принимали геометрический характер изложения, и диссертацию, написанную на геометрическом языке, могли и не пропустить. Петербургская академия наук отметила цикл работ Вороного по алгебраической теории чисел престижной премией имени В.Я.Буняковского.

Впоследствии алгоритм Вороного активно использовал Б.Н.Делоне в своих знаменитых исследованиях по диофантовым уравнениям третьей степени. Надо сказать, что Борис Николаевич Делоне (18901980) был наиболее последовательным продолжателем Вороного. Делоне не был и не мог быть его непосредственным учеником, поскольку Вороной умер в 1908 году, в том самом году, когда Борис Делоне поступил в Киевский университет. Тем не менее, Делоне близко знал Вороного. Дело в том, что Вороной познакомился и подружился с его отцом, профессором математики и механики Николаем Борисовичем Делоне, работавшим с 1900 по 1904 годы в Варшавском политехническом институте. Борис Николаевич любил вспоминать, как Вороной приходил к ним на ужин и допоздна засиживался за беседой с его отцом. А он, десятилетний мальчик, лежа в кровати, прислушивался к беседе, доносившейся из гостиной в его комнату через слегка неприкрытую дверь...

Судьбе было угодно, что в конце XX века имена Вороного и Делоне навсегда вошли в математику, более того, они оказались неразрывно связанными. Это так называемые диаграммы Вороного и триангуляции Делоне - понятия, важные в самых разных областях науки и ее приложений. (Во второй части статьи мы объясним, что такое диаграмма Вороного и как она связана с триангуляцией Делоне, описание которой было дано в Кванте №1, 2 за 2010 год в статье «Многогранный Делоне»).

После исследований по теории алгебраических чисел Вороной опубликовал в 1903 году большую работу по аналитической теории чисел, посвященную задаче о делителях, поставленной Дирихле. Нужно было оценить при больших $n$ сумму

$$
S(n)=\tau(1)+\tau(2)+\ldots+\tau(n),
$$

где $\tau(k)-$ количество простых делителей числа $k$. 
Нетрудно понять, что $S(n)$ равно количеству точек $(x ; y)$ с целыми положительными координатами, произведение которых не превосходит $n$ : $x y \leq n$. Так как

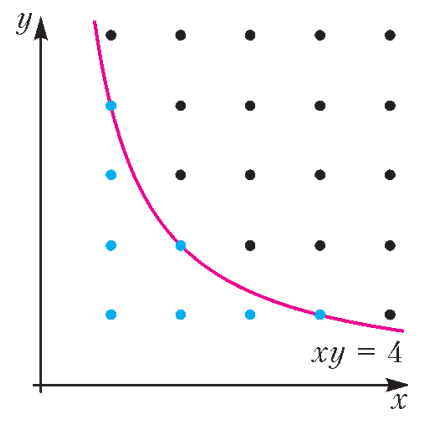

$x y=n$ есть уравнение гиперболы, то эта задача получила название проблемы целых точек под гиперболой (см. рисунок).

В своей работе 1849 года Дирихле получил для $S(n)$ следующую формулу:

$$
S(n)=n(\ln n+2 \gamma-1)+K_{n} \sqrt{n},
$$

где $\gamma=0,57721 \ldots$ - константа Эйлера и значение $\left|K_{n}\right|$ ограниченно при $n \rightarrow \infty$. В дальнейшем на протяжении полувека многочисленные усилия известных математиков, направленные на уточнение порядка относительно $n$ второго слагаемого в (1) (или, как говорят математики, остаточного члена), оставались безуспешными. И только в 1903 году Г.Ф.Вороной, основательно развив метод Дирихле, в результате сложных вычислений улучшил порядок остаточного члена в формуле (1) для $S(n)$ :

$$
S(n)=n(\ln n+2 \gamma-1)+\theta_{n} \sqrt[3]{n} \ln n,
$$

где значение $\theta_{n}$ ограничено некоторой постоянной при $n \rightarrow \infty$.

Работа Вороного о числе целых точек под гиперболой оказала влияние на творчество ряда замечательных математиков, в частности Ивана Матвеевича Виноградова, в будущем основателя и директора Математического института имени В.А.Стеклова. А ученик Вороного Серпинский успешно применил его метод к другой классической задаче о числе $A(n)$ целых точек $(x ; y)$ в круге $x^{2}+y^{2} \leq n$.

Итак, варшавский период начался с исследований по теории алгебраических чисел. Затем последовала атака на аналити- ческую проблему точек под гиперболой. Последние 4 года этого периода и, к глубокому сожалению, жизни в целом, Вороной посвятил труднейшим задачам геометрии чисел. Одна из них - задача нахождения плотнейшей упаковки пространства равными шарами. Другая - задача нахождения всех параллелоэдров - многогранников, которые заполняют пространство своими копиями, расположенных параллельно друг другу. Именно здесь, на геометрическом направлении, Вороной получает свои самые интересные и глубокие результаты. Мы опишем их во второй части статьи.

\section{О НЕматематике}

В Варшавском университете Вороной проработал с 1894 года до конца жизни с небольшим перерывом. В связи с революционными волнениями 1905-1907 годов Варшавский университет был закрыт, и Вороной был направлен на работу в Новочеркасск, в только что организованный там Донской политехнический институт, где в $1907 / 08$ учебном году был деканом факультета механики. В 1907 году за выдающиеся научные достижения Вороной был избран членом-корреспондентом Петербургской академии наук.

Г.Ф.Вороной был женат на Ольге Митрофановне Крицкой, девушке из дворянской семьи, чье имение Богданы находилось поблизости от его Журавки. Ольга была его большая и единственная любовь. У них было шестеро детей. Помимо своей многочисленной семьи, Вороной заботился также о семье рано овдовевшей сестры с семью детьми. Все дети Георгия Феодосьевича получили хорошее образование и стали врачами, учителями. Младший сын Юрий Георгиевич Вороной (1896-1961), хирург, доктор медицинских наук, прославился тем, что в 1933 году сделал первую в мире пересадку почки.

Г.Ф.Вороной не отличался крепким здоровьем, в последние годы страдал от прогрессирующей болезни желчного пузыря. Интенсивная научная и преподавательская работа усугубляла болезнь. В последний год жизни врачи настаивали на отды- 
хе. Вороной и сам отчетливо понимал, что напряженная работа отрицательно сказывается на здоровье, но оставить исследования было выше его сил. «Только моя жена знает, что математика является для меня главной целью жизни, она для меня - все», - записал он в дневнике.

Лето 1908 года Георгий Феодосьевич провел в родной Журавке, несмотря на рекомендации врачей поехать на лечение в Карлсбад. К началу учебного года ему становится легче, и он возвращается в Варшаву. В начале сентября пишет, как оказалось, последнее письмо академику В.А.Стеклову, в котором кратко сообщает о своих исследованиях по теории параллелоэдров, а также выражает желание перейти в Петербургский университет.

Однако в октябре наступило резкое обострение болезни. В последний месяц жизни, страдая от болей, прикованный к постели, Вороной сумел записать «Заметки по поводу последней теоремы Ферма». Через две недели, 7(20) ноября 1908 года, в возрасте сорока лет Георгий Феодосьевич Вороной скончался. Похоронен по завещанию в его любимой Журавке.

\section{(Продолжение следует)}

\section{КОНКУРС ИМЕНИ А.П.САВИНА}

Мы продолжаем очередной конкурс по решению математических задач. Они рассчитаны в первую очередь на учащихся 7-9 классов, но мы будем рады участию школьников всех возрастов. Конкурс проводится совместно с журналом "Квантик".

Высылайте решения задач, с которыми справитесь, электронной почтой по адресу: savin.contest@gmail.com или обычной почтой по адресу: 119296 Москва, Ленинский проспект, 64-А, “Квант" (с пометкой “Конкурс имени А.П.Савина»). Кроме имени и фамилии укажите город, школу и класс, в котором вы учитесь, а также обратный почтовый адрес.

Мы приветствуем участие в конкурсе не только отдельных школьников, но и команд (в таком случае присылается одна работа со списком участников). Участвовать можно, начиная с любого тура. Победителей ждут дипломы журнала “Квант» и призы. Задания, решения и результаты публикуются на сайте sites.google.com/view/savin-contest

Желаем успеха!

13. Можно ли рассадить за круглым столом через равные промежутки между людьми а) 20, б) 19 молчунов и несколько болтунов так, чтобы напротив каждого молчуна сидел болтун и чтобы никакие два болтуна не сидели рядом?

\section{А.Ковальджи}

14. Окружность пересекает стороны треугольника в 6 точках (см. рисунок).

a) Докажите, что если $a=b$ и $c=d$, то $e=f$.

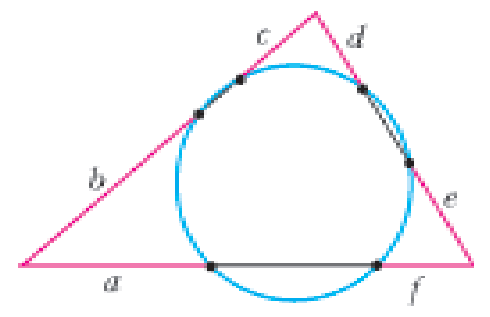

б) Докажите, что если $b=c$ и $d=e$, то $f=a$.

\section{Е.Бакаев}

15. Пусть $A$ - наименьшее, а $B$ - наибольшее из восьмизначных чисел, в записи которых присутствует каждая из цифр 1, $2, \ldots, 8$ и которые делятся на 137. Докажите, что $A+B$ делится на 73.

\section{С.Костин}

16. Обозначим как $P_{N}$ число способов выбрать из $N$ различных предметов любое количество предметов, дающее остаток 1 при делении на 3 , а как $Q_{N}$ - число способов выбрать из $N$ различных предметов любое количество предметов, дающее остаток 2 при делении на 3. Докажите, что $P_{N}$ и $Q_{N}$ отличаются не больше чем на 1. E.Бакаев 